\title{
CFD simulation and experimental measurement of gas holdup and liquid interstitial velocity in internal loop airlift reactor
}

\author{
M. Šimčík ${ }^{a, *}$, A. Mota ${ }^{b}$, M.C. Ruzicka ${ }^{a}$, A. Vicente $^{b}, J$. Teixeira ${ }^{b}$ \\ ${ }^{a}$ Institute of Chemical Process Fundamentals, Czech Academy of Sciences, Rozvojova 135, 16502 Prague 6, Czech Republic \\ ${ }^{\mathrm{b}}$ Institute for Biotechnology and Bioengineering, Centre of Biological Engineering, University of Minho, Campus de Gualtar, 4710-057 Braga, Portugal
}

\section{A R T I C L E I N F O}

\section{Article history:}

Received 30 September 2010

Received in revised form

28 January 2011

Accepted 31 January 2011

Available online 5 February 2011

\section{Keywords:}

Airlift

CFD

Hydrodynamics

Multiphase flow

Multiphase reactors

Simulation

\begin{abstract}
A B S T R A C T
This paper documents experiments and CFD simulations of the hydrodynamics of our two-phase (water, air) laboratory internal loop airlift reactor $(40 \mathrm{l})$. The experiments and simulations were aimed at obtaining global flow characteristics (gas holdup and liquid interstitial velocity in the riser and in the downcomer) in our particular airlift configurations. The experiments and simulations were done for three different riser tubes with variable length and diameter. Gas (air) superficial velocities in riser were in range from 1 to $7.5 \mathrm{~cm} / \mathrm{s}$. Up to three circulation regimes were experimentally observed (no bubbles in downcomer, bubbles in downcomer but not circulating, and finally the circulating regime). The primary goal was to test our CFD simulation setup using only standard closures for interphase forces and turbulence, and assuming constant bubble size is able to capture global characteristics of the flow for our experimental airlift configurations for the three circulation regimes, and if the simulation setup could be later used for obtaining the global characteristic for modified geometries of our original airlift design or for different fluids. The CFD simulations were done in commercial code Fluent 6.3 using algebraic slip mixture multiphase model. The secondary goal was to test the sensitivity of the simulation results to different closures for the drag coefficient and the resulting bubble slip velocity and also for the turbulence. In addition to the simulations done in Fluent, simulation results using different code (CFX 12.1) and different model (full Euler-Euler) are also presented in this paper. The experimental measurements of liquid interstitial velocity in the riser and in the downcomer were done by evaluating the response to the injection of a sulphuric acid solution measured with $\mathrm{pH}$ probes. The gas holdup in the riser and downcomer was measured with the U-tube manometer. The results showed that the simulation setup works quite well when there are no bubbles present in the downcomer, and that the sensitivity to the drag closure is rather low in this case. The agreement was getting worse with the increase of gas holdup in the downcomer. The use of different multiphase model in the different code (CFX) gave almost the same results as the Fluent simulations.
\end{abstract}

(c) 2011 Elsevier Ltd. All rights reserved.

\section{Introduction}

Airlift reactors are pneumatically agitated vessels, and are one among different types of multiphase reactors. They possess good mixing, mass and heat transfer characteristics and they are used in a wide range of industrial applications such as waste water treatment, chemical (e.g. hydrogenations and oxidations) and biochemical processes, and others. The other advantages are simplicity of construction, absence of moving parts, and low power consumption. Their other advantageous features in case of biochemical processes are ease of long term sterile operation, and a hydrodynamic environment suitable for fragile biocatalysts,

\footnotetext{
* Corresponding author.

E-mail address: simcik@icpf.cas.cz (M. Šimčík).
}

which are susceptible to physical damage by fluid turbulence or mechanical agitation (Chisti, 1998).

The airlift reactor consists of two interconnected main parts, the riser and the downcomer. Gas is injected into the riser and the resulting difference between average densities in the riser and in the downcomer provides a driving force for liquid circulation. Also solid particles can be present (catalyst, biomass, etc.). There are two main groups of airlift reactors namely, the internal loop airlift reactor and the external loop airlift reactor. The internal loop airlift reactor is a bubble column divided into the two parts by a draft tube inserted into the column. The external loop airlift consists of two separate columns connected with pipes. Other important part, which may or may not be present, is the gas separator. Its purpose is to prevent bubbles from being entrained into the downcomer, which would decrease the driving force for liquid circulation. 
The knowledge of the airlift hydrodynamics is needed for the design of the airlift reactor. Basic global quantities such as gas holdup and liquid velocities in the riser and in the downcomer, total interfacial area, and others are needed to be known. The hydrodynamic and other relevant parameters such as the airlift geometry are interrelated and their relationship can be quite complex and they directly or indirectly influence each other in sometimes not so obvious ways (Chisti, 1998), e.g. the driving force for the liquid circulation is the difference in gas holdups between the riser and the downcomer. This driving force is balanced by friction losses in the riser and the downcomer and in the bottom and top parts of the reactor (influence of bottom and top clearances in the case of internal loop airlifts or losses in connecting pipes in the case of external airlifts and of the airlift geometry in general). However, the resulting liquid circulation in turn affects the riser and downcomer gas holdup and thus the driving force. The gas holdup depends also on bubble slip velocity, which depends on the bubble size. Bubble size is influenced by the gas distributor, coalesce properties of the involved fluids and by turbulence. Turbulence is influenced by liquid circulation, etc.

The relevant hydrodynamic parameters need to be either obtained experimentally or predicted by models of various types. A lot of experimental data have been published in the past on global quantities (holdup, liquid velocities) in airlift reactors and correlations based on these data. A large number of correlations for these parameters are compiled in Chisti (1989), other can be, e.g., in Chisti (1998).

Many of the correlations presented in the literature are restricted in their validity to the same reactor size, type and gasliquid system used in their development (Young et al., 1991). As a rule, these correlations are system specific, being of little use in design or scaleup, where the usual requirement is for estimation of expected performance in larger or geometrically different reactors or fluids (Chisti, 1998). Some authors employed models based on mechanical energy balance in the airlift reactor, e.g. Verlaan et al. (1986), Chisti (1989), and Heijnen et al. (1997). However, information about friction losses (friction coefficients) must be provided as an input parameter for these models. More recent experimental measurements of airlift global hydrodynamic characteristics (riser and downcomer holdup and velocities) can be found, e.g., in van Baten et al. (2003), Blazej et al. (2004), Merchuk et al. (1998) and van Benthum et al. (1999) (internal loop airlifts) or in Freitas et al. (2000) and Vial et al. (2002) (external loop airlifts). There were also papers published on local gas holdup and/or local liquid velocity measurements. Luo and Al-Dahhan $(2008,2010)$ measured liquid velocity profiles, turbulent quantities using the CARPT technique and gas holdups profiles using computed tomography in an internal loop airlift reactor. They observed significant effect of top and bottom clearances on the flow. They also observed that the bubbles are prone to concentrate in the riser center in radial direction and the change from bubbly to churn-turbulent flow at superficial gas velocity of $2 \mathrm{~cm} / \mathrm{s}$. Local gas holdups and/or liquid velocities in external loop airlift reactors were measured, e.g. by Young et al. (1991), Vial et al. (2002), Wang et al. (2004), Cao et al. (2007), Utiger et al. (1999), or Lin et al. (2004).

Apart from experiments, empirical correlations or theoretical models such as the models based on mechanical energy balance, CFD simulations can be an another tool, which can be used to study airlift hydrodynamics. There are two main groups of multiphase flow models usable for simulations on bubble column/airlift scale. In Euler-Euler models all phases are treated as interpenetrating continua, while in Euler-Lagrange models the motion of individual particles is tracked through the continuous fluid. The EulerLagrange models, which track the motion of every single particle (approximated as a mass point with closure equation for the interphase forces), can be used for smaller scale problems with low gas holdup. Only Euler-Euler models (mixture model and "full"
Euler-Euler model) were used in the presented work, thus only Euler-Euler models are considered in the following text. The main advantage of CFD simulations if compared to experiments is that no experimental apparatus has to be built; the equipment dimensions and working fluids can be easily changed in simulations; etc. However, the quality of the CFD simulation predictions, of course, greatly depends on how well or how badly the employed CFD models, submodels and closure equations describe flow phenomena occurring in the airlift reactor. Since the gas-liquid flows are very complex with flow phenomena occurring on a wide range of space and time scales, modeling of gas-liquid flows is still an open subject and far from being complete. It is still necessary to validate simulation results against experiments. Euler-Euler models need closures for all relevant interphase force (drag, lift, added mass, etc.), for the turbulence (due to single phase flow and due to bubbles) and models for bubble coalescence and break-up, because the bubble size figures in most of the closure equations. Sokolichin et al. (2004) discussed the relevance of individual interphase forces for the simulation and also turbulence modeling issues in their review paper. They observed a weak dependency of simulation results (in partially aerated rectangular bubble column) on the employed value of the bubble slip velocity. They explained this weak dependence by the fact that the bubble total velocity was the sum of the bubble slip velocity and the liquid velocity, which can be relatively high, so the change in the bubble slip velocity had lower impact on the calculated gas holdup. It could be expected from the same reason that the similar behavior (weak dependence of gas holdup on the bubble slip velocity) could be found in airlift simulations, if bubbles are present only in the riser and the downcomer holdup is zero, and may be the dependence could be even weaker due to the more ordered flow in the airlift if compared to the bubble column. However, if there is nonzero gas holdup in the downcomer, then the effect of the bubble slip velocity could be much stronger due to countercurrent flow of both phases in the downcomer. It is then not surprising that some authors did simulations of airlifts and obtained good agreement with experiments even when inappropriate closure for drag force was used (e.g. Schiller-Naumann correlation for rigid sphere drag used for $5 \mathrm{~mm}$ equivalent diameter air bubble in water) in cases with zero downcomer gas holdup.

There are a number of papers dedicated to the Euler-Euler CFD simulations of airlift reactors.

External loop airlift simulation comparisons of radial profiles of gas holdup and liquid velocity can be found, e.g. in Vial et al. (2002), Roy et al. (2006), or Cao et al. (2007). The comparison of average gas holdup and liquid velocities with experiments for internal loop airlifts and for zero downcomer gas holdup can be found, e.g. in Mudde and van den Akker (2001) (rectangular airlift), van Baten et al. (2003), or in Huang et al. (2008), who also reported weak dependence of the simulation results on the bubble velocity prescribed on the top boundary condition. Simulations for cases with nonzero downcomer holdup were done, e.g. by Oey et al. (2001), Huang et al. (2010), Talvy et al. (2007) or Jia et al. (2007). Talvy et al. (2007) compared vertical and horizontal profiles of gas holdup in riser and downcomer, and horizontal liquid velocity profiles in downcomer with experiments in a rectangular airlift. Jia et al. (2007) compared simulated and experimental horizontal profiles of gas holdup and liquid in a rectangular airlift and found a good agreement.

\section{Goals}

The primary goal was to test the ability of our CFD simulation setup to capture global characteristics of the flow in our experimental 501 internal loop airlift with enlarged degassing zone (riser and downcomer mean liquid interstitial velocities and gas 
holdup) in the three experimentally observed bubble circulation regimes, and so verify if the simulation setup could be later used for obtaining the global characteristic for modified geometries of our original airlift design or for different fluids. The comparison was done for three different riser tubes. The CFD simulations were done in commercial code Fluent 6.3 using algebraic slip mixture multiphase model. Simulations results using different model (full Euler-Euler) in different code (CFX 12.1) are also presented in the paper. The experimental and simulation setups are described in Sections 3 and 4, respectively.

The secondary goal was to test the sensitivity of the simulations to the different bubble slip velocity, and to the different turbulence closure models (variants of $k-\varepsilon, k-\omega$ ). This was done using the mixture model in Fluent 6.3 code.

\section{Experimental setup}

The experiments were done in an internal loop airlift reactor with enlarged degassing zone. The total volume of the apparatus

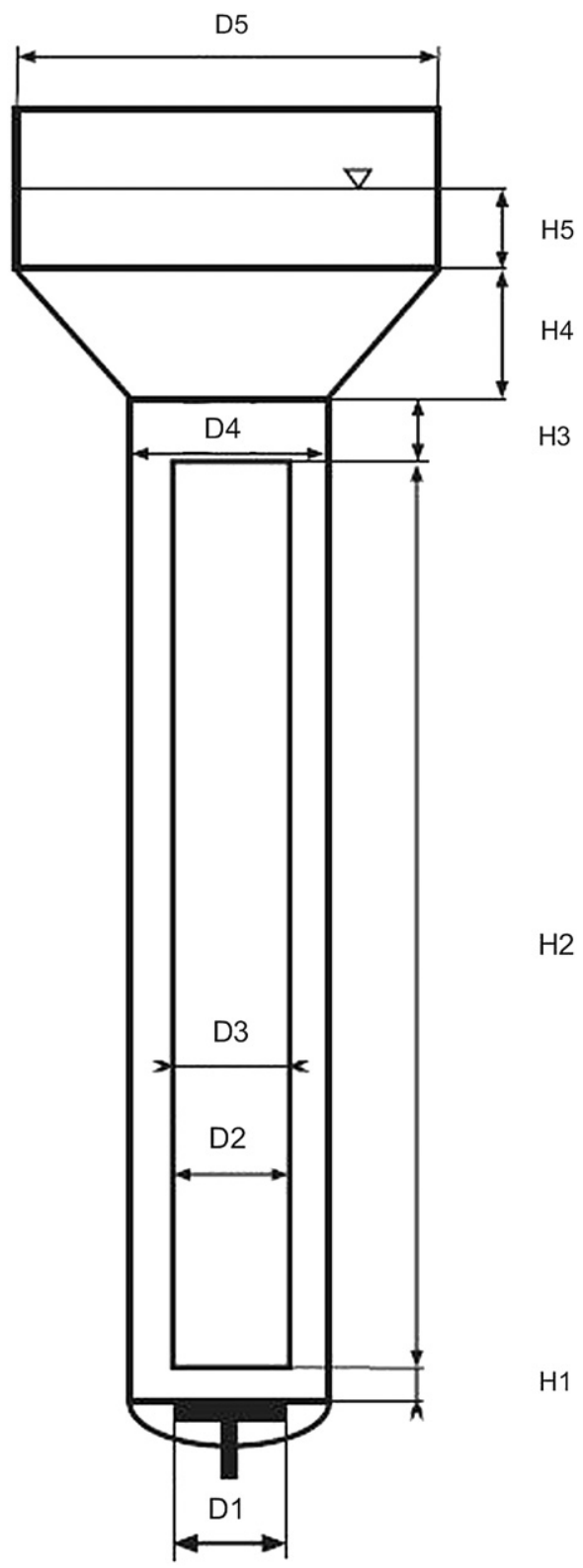

Fig. 1. Airlift geometry (not in scale).
Table 1

Airlift dimensions for configurations case A, case B and case $C$, and \# of grid cells per these dimensions in simulations (See Fig. 1).

\begin{tabular}{|c|c|c|c|c|c|c|}
\hline & \multicolumn{2}{|l|}{ Case A } & \multicolumn{2}{|l|}{ Case B } & \multicolumn{2}{|l|}{ Case C } \\
\hline & $(\mathrm{mm})$ & $\begin{array}{l}\# \text { of } \\
\text { grid cells }\end{array}$ & $(\mathrm{mm})$ & $\begin{array}{l}\# \text { of } \\
\text { grid cells }\end{array}$ & $(\mathrm{mm})$ & $\begin{array}{l}\# \text { of } \\
\text { grid cells }\end{array}$ \\
\hline D1 & 100 & 12 & 100 & 12 & 100 & 12 \\
\hline D2 & 62 & 12 & 87 & 12 & 62 & 12 \\
\hline D3 & 70 & 14 & 92 & 14 & 70 & 14 \\
\hline D4 & 142 & 28 & 142 & 28 & 142 & 28 \\
\hline D5 & 420 & 28 & 420 & 28 & 420 & 28 \\
\hline $\mathrm{H} 1$ & 23 & 5 & 23 & 5 & 23 & 5 \\
\hline $\mathrm{H} 2$ & 1200 & 60 & 1200 & 60 & 1400 & 70 \\
\hline H3 & 200 & 16 & 200 & 20 & 0 & 0 \\
\hline $\mathrm{H} 4$ & 170 & 14 & 170 & 12 & 170 & 14 \\
\hline H5 & 120 & 6 & 120 & 6 & 120 & 6 \\
\hline
\end{tabular}

was $50 \mathrm{l}$. The downcomer inner diameter was $14.2 \mathrm{~cm}$. Measurements were done for three different riser tubes: $120 \times 6.2 \mathrm{~cm}$ (case A), $120 \times 8.7 \mathrm{~cm}$ (case B) and $140 \times 6.2 \mathrm{~cm}$ (case C) (height $\times$ inner diameter). The airlift geometry is depicted in Fig. 1 and the relevant dimensions are summarized in Table 1 . The gas was entering the airlift through the $10 \mathrm{~cm}$ diameter porous plate sparger. The diameter of the "active" zone of the sparger, through which the gas flow was passing, was $\sim 8 \mathrm{~cm}$. Air and tap water were used as the gas and liquid phase. Gas superficial velocities in the riser were in range from 1 to $7.5 \mathrm{~cm} / \mathrm{s}$. The net water flow through the airlift was zero.

The liquid interstitial velocity in the riser and in the downcomer were measured with four $\mathrm{pH}$ probes (two Methrom model 620 probes in the riser and two model 691 probes in the downcomer) and evaluated from the probe signal response to a sulphuric acid solution injection. The probe signal was monitored and the data stored using Labview program. The signal sampling rate was $10 \mathrm{~Hz}$. The mean liquid interstitial velocity $\left(V_{L}=U_{L} / \alpha_{L}\right)$, was estimated as $V_{L}=\left(x_{2}-x_{1}\right) /\left(t_{2}-t_{1}\right)$, where $x_{1,2}$ are probe vertical positions and $t_{1,2}$ are probe signal peak times. The probes were placed at $x=8.4$ and $117.5 \mathrm{~cm}$ in the riser, and at $x=9.0$ and $117.5 \mathrm{~cm}$ in the downcomer ( $x=0$ being the sparger level). The reported values of interstitial liquid velocity are four measurements averages. The interstitial liquid velocity was measured in the downcomer in cases $A$ and $C$, and the riser velocity was calculated from a continuity equation. It was done the opposite way in case $B$.

The tracer was injected into the downcomer $18.4 \mathrm{~cm}$ above the gas distributor ( $10 \mathrm{ml}$ of $4.5 \mathrm{M} \mathrm{H}_{2} \mathrm{SO}_{4}$ solution). Initial $\mathrm{pH}$ inside the airlift was 10 and was set by the addition of $\mathrm{NaOH}$ solution prior to the start of the measurement.

The gas holdups in the riser and downcomer were estimated using U-tube manometers. The agreement of this estimate with the real gas holdup in the apparatus may be affected by a pressure drop due to flow.

\section{Simulation setup}

The main part of the simulations was done in CFD code Fluent 6.3 using the algebraic slip mixture model and the simulation setup is described in detail in Section 4.1. A part of the Fluent simulations was later recalculated in the CFX 12.1 code using the full Euler-Euler model and their results are also presented in this paper, although the case $B$ CFX simulations were not finished due to convergence problems and the results are not shown. The CFX setup is described in Section 5.2. The airlift geometry is shown in Fig. 1. The gas distributor in the simulation domain geometry 

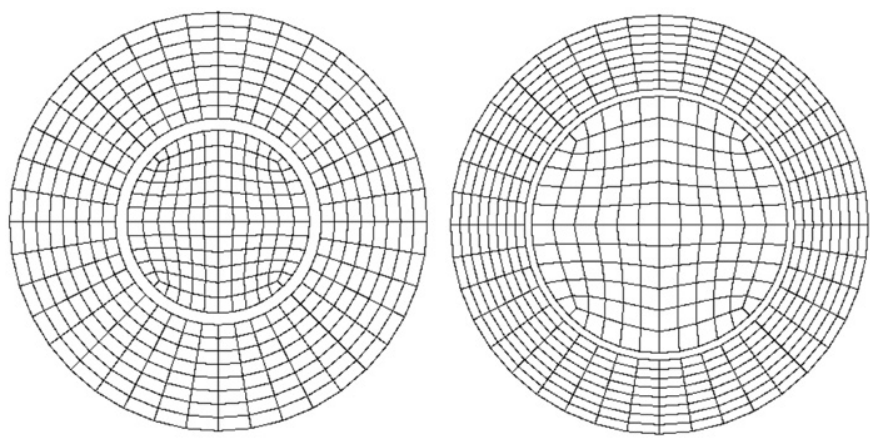

Fig. 2. Computational grid for cases $A$ and $C$ (left), and case $B$ (right) at the airlift cross-section.

had the same diameter as the riser. The computational grid was the same for both Fluent and CFX simulations and contained 48,100 (case A), 49,100 (case B) and 44,700 (case $C$ ) grid cells. The computational grid (at the airlift cross-section) is shown in Fig. 2 and number of grid cells per each airlift dimension can be found in Table 1. The grid was sufficient to obtain grid independent results (see Section 5.1 for the grid independence test result). The timestep in all simulations was $0.005 \mathrm{~s}$.

\subsection{Fluent simulations}

The mixture model was employed for simulations done in Fluent 6.3 code. The model assumes that two or more phases are interpenetrating. It can solve cases, where two or more phases move at different velocities and it assumes local equilibrium over short spatial length scales, i.e. dispersed phases move at their terminal velocities. This model is simpler than full Euler-Euler multiphase model. The mixture model solves the continuity and the momentum equation for a mixture with averaged mixture properties (density, velocity, and viscosity), an algebraic equation for the dispersed phase(s) slip velocity and a volume fraction equation for the secondary phase(s). The mixture model should require less computational resources than the Euler-Euler model, since it solves fewer equations. However, it can be sometimes more difficult to converge with more iterations required to be done, thus diminishing the mentioned advantage over the EulerEuler model. Model equations, boundary conditions and other solver parameters are described in following paragraphs.

The algebraic slip mixture model solves the continuity and momentum equation for the mixture, the algebraic equation for dispersed phase slip velocity and volume fraction equation for the secondary phase to update the composition of the mixture due to flow (Manninen et al. 1996), and finally the turbulence model is solved to provide the closure for the turbulent viscosity, which appears in the momentum equation for the mixture.

Continuity equation

The mixture continuity equation is

$\partial \rho_{m} / \partial t+\nabla \cdot\left(\rho_{m} \mathbf{v}_{\mathbf{m}}\right)=0$

where $\mathbf{v}_{\mathbf{m}}=\left(1 / \rho_{m}\right) \sum_{k=1}^{n} \alpha_{k} \rho_{k} \mathbf{v}_{\mathbf{k}}$ is the mixture mass averaged velocity, and $\rho_{m}=\sum_{k=1}^{n} \alpha_{k} \rho_{k}$ is the mixture density, $\alpha_{k}$ is the $k$-th phase volume fraction. The sums are over all $(n)$ phases $(k)$.

Momentum equation

The mixture momentum equation is

$$
\begin{aligned}
& \partial\left(\rho_{m} \mathbf{v}_{\mathbf{m}}\right) / \partial t+\nabla \cdot\left(\rho_{m} \mathbf{v}_{\mathbf{m}} \mathbf{v}_{\mathbf{m}}\right)=-\nabla p+\nabla \cdot\left[\mu_{m}\left(\nabla \mathbf{v}_{\mathbf{m}}+\nabla \mathbf{v}_{\mathbf{m}}^{\mathbf{T}}\right)\right]+\rho_{m} \mathbf{g} \\
& \quad+\nabla \cdot\left(\sum_{k=1}^{n} \alpha_{k} \rho_{k} \mathbf{v}_{\mathbf{d r}, \mathbf{k}} \mathbf{v}_{\mathbf{d r}, \mathbf{k}}\right)
\end{aligned}
$$

where $n$ is the number of phases (2 in our case), $\mu_{m}=\left(\sum_{k=1}^{n} \alpha_{k} \mu_{k}\right)+\mu_{t}$ is the mixture effective viscosity, $\mu_{t}$ is the turbulent viscosity and $\mu_{k}$ is the molecular viscosity of phase $k$. The $k$-th phase drift velocity is calculated as $\mathbf{v}_{\mathbf{d r}, \mathbf{k}}=\mathbf{v}_{\mathbf{k}}-\mathbf{v}_{\mathbf{m}}=\mathbf{v}_{\mathbf{k c}}{ }^{-}$ $\left(1 / \rho_{m}\right) \sum_{i=1}^{n} \alpha_{i} \rho_{i} \mathbf{v}_{\mathbf{i c}}$, where $\mathbf{v}_{\mathbf{k c}}=\mathbf{v}_{\mathbf{k}}-\mathbf{v}_{\mathbf{c}}$ is the slip velocity of the phase $k$ ( $c$ index is for the continuous phase).

Equation for the $k$-th phase slip velocity

The $k$-th phase slip velocity is calculated from the following algebraic equation:

$\mathbf{v}_{\mathbf{k c}}=\tau_{k}\left(\rho_{k}-\rho_{c}\right) \mathbf{a} /\left(f \rho_{k}\right)-\left(\eta_{t} / \sigma_{t}\right)\left(\nabla \alpha_{k} / \alpha_{k}-\nabla \alpha_{c} / \alpha_{c}\right)$

The first term on the right hand side of Eq. (3) is due to the drag force, where $\tau_{k}=\rho_{k} d_{k}^{2} /\left(18 \mu_{c}\right)$ is k-phase particle relaxation time, $f=C_{D} \operatorname{Re} / 24$ is a drag function, $\operatorname{Re}=d_{k}\left|\mathbf{v}_{\mathbf{k c}}\right| \rho_{c} / \mu_{c}$, acceleration $\mathbf{a}=\mathbf{g}-\left(\mathbf{v}_{\mathbf{m}} \cdot \nabla\right) \mathbf{v}_{\mathbf{m}}-\partial \mathbf{v}_{\mathbf{m}} / \partial t$ and $C_{D}$ is drag coefficient. The drag coefficient $C_{D}$ was calculated from Tomiayama's correlation (Tomiyama et al., 2002) for a single bubble:

$$
C_{D}=\max \left[\min \left\{24 / \operatorname{Re}\left(1+0.15 \operatorname{Re}^{0.687}\right), 72 / \operatorname{Re}\right\},(8 / 3) \mathrm{Eo} /(\mathrm{Eo}+4)\right]
$$

where Eo $=\left(\rho_{L}-\rho_{G}\right) g d^{2} / \sigma$. The bubble equivalent diameter $d$ in simulations was set to $5 \mathrm{~mm}$. Previously done visual observations of the bubbly flow using a high speed camera, suggest that this bubble diameter could reasonably well represent the typical bubble size in our airlift, at least for lower gas flow rates. (However these experiments were done for a bubble column and not the airlift configuration of our experimental unit, and were done only for low gas flow rates due to the opaqueness of the bubbly layer.) The drag coefficient calculated from (4a) is $C_{D}=1.215$ for a single $5 \mathrm{~mm}$ bubble, with a corresponding slip velocity $\sim 0.23 \mathrm{~m} / \mathrm{s}$. All bubbles were assumed to be of the same size, there was no bubble break-up/coalescence model employed in our simulations.

Another closure, Schiller-Naumann, was employed just for test purposes to examine an effect of bubble slip velocity on the simulation results (see Section 5.1)

$$
\begin{aligned}
& C_{D}=24 / \operatorname{Re}\left(1+0.15 \operatorname{Re}^{0.687}\right) \text { for } \operatorname{Re}<1000 \\
& C_{D}=0.44 \text { for } \operatorname{Re}>1000
\end{aligned}
$$

However, all other presented simulations used the previous Eq. (4a) for calculating the drag coefficient.

The second term on the right hand side of Eq. (3) appears due to a dispersion of secondary phase by turbulence. The $\sigma_{t}$ is the turbulent Prandtl number and $\eta_{t}$ is the turbulent diffusivity calculated from

$$
\begin{aligned}
& \eta_{t}=\mathrm{C}_{\mu} k^{2} / \varepsilon\left(\gamma_{\gamma} /\left(1+\gamma_{\gamma}\right)\left(1+\mathrm{C}_{\beta} \zeta_{\gamma}^{2}\right)^{-1 / 2}\right. \\
& \zeta_{\gamma}=\left|\mathbf{v}_{\mathbf{k c}}\right| /(2 / 3 k)^{1 / 2} \\
& C_{\beta}=1.8-1.35 \cos ^{2} \theta \\
& \theta=\mathbf{v}_{\mathbf{k c}} \mathbf{v}_{\mathbf{k}} /\left(\left|\mathbf{v}_{\mathbf{k c}}\right|\left|\mathbf{v}_{\mathbf{k}}\right|\right) \\
& C_{\mu}=0.09
\end{aligned}
$$

The $\gamma_{\gamma}$ is a time ratio between the time scale of the energetic turbulent eddies affected by the crossing-trajectories effect, see Fluent user's guide. The value of $\sigma_{t}$ was set to 0.01 . The default value was 0.75 . The lower value, which was used in our Fluent simulations, enhances a turbulent dispersion. The lower value was chosen, because for case $B$ bubbles flowing into the riser did not disperse fast enough across the whole riser cross section as it was visually observed in experiments.

Phase volume fraction equation for the secondary phase

The mixture composition is updated by solving the transport equation for the dispersed phases (only one dispersed phase in our case)

$\partial\left(\alpha_{k} \rho_{k}\right) / \partial t+\nabla \cdot\left(\alpha_{k} \rho_{k} \mathbf{v}_{\mathbf{m}}\right)=-\nabla \cdot\left(\alpha_{k} \rho_{k} \mathbf{v}_{\mathbf{d r}, \mathbf{k}}\right)$ 


\section{Turbulence model}

The standard $k-\varepsilon$ model was used to model turbulence. This model belongs to a group of Reynolds averaged Navier-Stokes equation models. The instantaneous velocity in the momentum equation is divided into the average and fluctuating part $\mathbf{u}=\mathbf{v}_{\mathbf{m}}+\mathbf{v}^{\prime}$. Then the momentum equation is ensemble averaged and the resulting term $-\nabla \cdot\left(\rho \mathbf{v}^{\prime} \mathbf{v}^{\prime}\right)$ is modeled as $\nabla \cdot\left[\mu_{t}\left(\nabla \mathbf{v}_{\mathbf{m}}+\nabla \mathbf{v}_{\mathbf{m}}^{\mathbf{T}}\right)\right]$, where $\mu_{t}$ is the turbulence viscosity, which again requires a closure equation. The closure is

$\mu_{t}=\rho_{m} C_{\mu} k^{2} / \varepsilon$

The turbulent kinetic energy $k$ and turbulent dissipation rate $\varepsilon$ are obtained by solving their transport equations

$$
\begin{aligned}
& \partial\left(\rho_{m} k\right) / \partial t+\nabla \cdot\left(\rho_{m} \mathbf{v}_{\mathbf{m}} k\right)=\nabla \cdot\left[\mu_{t, m} / \sigma_{k}(\nabla k)\right]+G_{k, m}-\rho_{m} \varepsilon \\
& \partial\left(\rho_{m} \varepsilon\right) / \partial t+\nabla \cdot\left(\rho_{m} \mathbf{v}_{\mathbf{m}} \varepsilon\right)=\nabla \cdot\left[\mu_{t, m} / \sigma_{\varepsilon}(\nabla \varepsilon)\right]+\varepsilon / k\left(C_{1 \varepsilon} G_{k, m}-C_{2 \varepsilon} \rho_{m} \varepsilon\right)
\end{aligned}
$$

Thus unlike the molecular viscosity, the turbulent viscosity is not a constant, but it depends on the local flow field. The term $G_{k, m}$ is a turbulence production due to mean velocity shear.

$G_{k, m}=\mu_{\mathrm{t}}\left[\nabla \mathbf{v}_{\mathbf{m}}+\left(\nabla \mathbf{v}_{\mathbf{m}}\right)^{\mathbf{T}}\right]: \nabla \mathbf{v}_{\mathbf{m}}$

The turbulent model constants were $C_{\mu}=0.09, \sigma_{k}=1, \sigma_{\varepsilon}=1.3$, $C_{1 \varepsilon}=1.44, C_{2 \varepsilon}=1.92$.

The boundary conditions were no-slip condition on all airlift walls. Standard wall function was used to model a velocity profile in the walls vicinity and to provide inner "boundary" condition for Reynolds averaged velocity field. Zero liquid velocity and $0.25 \mathrm{~m} / \mathrm{s}$ gas vertical velocity were prescribed at the inlet for all phases. Gas volume fraction was then set to a constant value to obtain the desired gas flow rate into the airlift. Zero liquid velocity was set at the outlet boundary and zero gradients were set for gas velocity and gas volume fraction (user defined function was used to do this). The initial condition was zero liquid velocity and gas volume fraction, initial turbulence kinetic energy was $k=0.001 \mathrm{~m}^{2} / \mathrm{s}^{2}$, and dissipation rate $\varepsilon=0.0001 \mathrm{~m}^{2} / \mathrm{s}^{3}$. The time interval of $30 \mathrm{~s}$ was then simulated to let the flow reach a steady or pseudosteady state. Then another $120 \mathrm{~s}$ or more of a flow time was simulated to obtain time-averaged quantities for evaluation.

The segregated pressure-based solver in Fluent was used to solve the model equations, node based gradient option was used to evaluate variables' gradients. PISO scheme was used as a pressure-velocity coupling algorithm, PRESTO! scheme was used for pressure discretization and the QUICK scheme for velocity, gas volume fraction, turbulence kinetic energy, and dissipation rate. A first order implicit scheme was employed for the time discretization.

\subsection{CFX simulations}

In addition to the simulations run in Fluent code (setup described in Section 4.1), some simulations were later recalculated in CFX 12.1 using Euler-Euler two-fluid model. Their setup is described in this section. Unlike the mixture model, this model solves continuity and momentum equation for each phase. Thus for a two phase flow there are two continuity and two momentum equations, one set for continuous phase $c$ and one for dispersed phase $d$. The two momentum equations are coupled together via pressure (pressure field is shared by both phases), and via interphase force terms, which accounts for various forces (drag, lift, added mass, turbulent dispersion force, and others) and cancel each other out when momentum equations of individual phases are added together. Drag force and turbulence dispersion force were accounted for in our CFX simulations. Other forces were not considered.
The continuity equations of continuous $(c)$ and dispersed $(d)$ phase are

$$
\begin{aligned}
& \partial \alpha_{c} \rho_{c} / \partial t+\nabla \cdot\left(\partial \alpha_{c} \rho_{c} \mathbf{v}_{\mathbf{c}}\right)=0 \\
& \partial \alpha_{d} \rho_{d} / \partial t+\nabla \cdot\left(\partial \alpha_{d} \rho_{d} \mathbf{v}_{\mathbf{d}}\right)=0
\end{aligned}
$$

The momentum equations of phase $c$ and $d$ are

$$
\begin{aligned}
\partial\left(\alpha_{c} \rho_{c} \mathbf{v}_{\mathbf{c}}\right) / \partial t+\nabla \cdot\left(\alpha_{c} \rho_{c} \mathbf{v}_{\mathbf{c}} \mathbf{v}_{\mathbf{c}}\right)= & -\alpha_{c} \nabla p+\nabla \cdot\left[\alpha_{c} \mu_{c, e f f}\left(\nabla \mathbf{v}_{\mathbf{c}}+\nabla \mathbf{v}_{\mathbf{c}}^{\mathbf{T}}\right)\right] \\
& +\alpha_{c} \rho_{\mathbf{c}} \mathbf{g}+\mathbf{M}_{\mathbf{c d}} \\
\partial\left(\alpha_{d} \rho_{d} \mathbf{v}_{\mathbf{d}}\right) / \partial t+\nabla \cdot\left(\alpha_{d} \rho_{d} \mathbf{v}_{\mathbf{d}} \mathbf{v}_{\mathbf{d}}\right)= & -\alpha_{d} \nabla p+\nabla \cdot\left[\alpha_{d} \mu_{d, e f f}\left(\nabla \mathbf{v}_{\mathbf{d}}+\nabla \mathbf{v}_{\mathbf{d}}^{\mathbf{T}}\right)\right] \\
& +\alpha_{d} \rho_{d} \mathbf{g}+\mathbf{M}_{\mathbf{d c}}
\end{aligned}
$$

where $\mathbf{M}_{\mathbf{c d}}=-\mathbf{M}_{\mathbf{d c}}$ is a force acting on the phase $\mathrm{c}$ due to phases $\mathrm{d}$ (drag, lift, etc.), and $\mu_{c, \text { eff }}$ and $\mu_{d, \text { eff }}$ are effective viscosities consisting of a molecular and a turbulent viscosity

$\mu_{c, \text { eff }}=\mu_{c}+\mu_{t c}$ and $\mu_{d, \text { eff }}=\mu_{d}+\mu_{t d}$

Only drag and turbulence dispersion force were considered in our simulations

$\mathbf{M}_{\mathbf{c d}}=\mathbf{M}_{\mathbf{c d}, \mathbf{D}}+\mathbf{M}_{\mathbf{c d}, \mathbf{T D}}$

$\mathbf{M}_{\mathbf{c d}, \mathbf{D}}=K_{c d}\left(\mathbf{v}_{\mathbf{d}}-\mathbf{v}_{\mathbf{c}}\right)=(3 / 4)\left(C_{D} / d\right) \alpha_{d} \rho_{c}\left|\mathbf{v}_{\mathbf{d}}-\mathbf{v}_{\mathbf{c}}\right|\left(\mathbf{v}_{\mathbf{d}}-\mathbf{v}_{\mathbf{c}}\right)$

where $d$ is dispersed phase particle (bubble) equivalent diameter. Drag coefficient was set to $C_{D}=1.215$ resulting in a bubble slip velocity $\sim 0.23 \mathrm{~m} / \mathrm{s}$ ( $\sim 5 \mathrm{~mm}$ bubble in water).

$\mathbf{M}_{\mathbf{c d}, \mathbf{T D}}=C_{T D} K_{c d} v_{\mathrm{tc}} / \sigma_{\mathrm{tc}}\left(\nabla \alpha_{d} / \alpha_{d}-\nabla \alpha_{c} / \alpha_{c}\right)$

where $C_{\mathrm{TD}}=1, K_{c d}$ is momentum transfer coefficient for drag force, $v_{t c}$ is turbulent kinematic viscosity of the continuous phase, $\sigma_{t c}=0.9$.

Two equation $k-\varepsilon$ model was used to model turbulence and to obtain a closure for turbulent viscosity in the continuous phase $\mu_{t c}$ :

$\mu_{t c}=C_{\mu} \rho_{c} k_{c}^{2} / \varepsilon_{c}$

$\partial\left(\alpha_{c} \rho_{c} k_{c}\right) / \partial t+\nabla \cdot\left(\alpha_{c} \rho_{c} \mathbf{v}_{c} k_{c}\right)=\nabla \cdot\left[\alpha_{c}\left(\mu_{c}+\mu_{t c} / \sigma_{k}\right)\left(\nabla k_{c}\right)\right]+\alpha_{c} G_{c}-\alpha_{c} \rho_{c} \varepsilon_{c}$

$\partial\left(\alpha_{c} \rho_{c} \varepsilon_{c}\right) / \partial t+\nabla \cdot\left(\alpha_{c} \rho_{c} \mathbf{v}_{\mathbf{c}} \varepsilon_{c}\right)=\nabla \cdot\left[\alpha_{c}\left(\mu_{c}+\mu_{t c} / \sigma_{\varepsilon}\right)\left(\nabla \varepsilon_{c}\right)\right]$

$+\alpha_{c} \varepsilon_{c} / k_{c}\left(C_{1 \varepsilon} G_{c}-C_{2 \varepsilon} \rho_{c} \varepsilon_{c}\right)$

where $G_{c}=\mu_{t c}\left[\nabla \mathbf{v}_{\mathbf{c}}+\left(\nabla \mathbf{v}_{\mathbf{c}}\right)^{\mathbf{T}}\right]: \nabla \mathbf{v}_{\mathbf{c}}$

The turbulent model constants were $C_{\mu}=0.09, \sigma_{k}=1, \sigma_{\varepsilon}=1.3$, $C_{1 \varepsilon}=1.44, C_{2 \varepsilon}=1.92$.

Turbulence viscosity in the dispersed phase $\mu_{t d}$ was calculated as

$\mu_{t d}=\left(\rho_{d} / \rho_{c}\right) \mu_{t c} / \sigma$

where $\sigma=1$.

The boundary conditions were no-slip condition for liquid and free-slip condition for gas phase on walls. Zero velocity for liquid and $0.25 \mathrm{~m} / \mathrm{s}$ for gas phase were used. The volume fraction of gas phase was set to obtain the desired value of gas flow rate. The "degassing" condition was used at the outlet-liquid velocity is to zero, while the gas phase is allowed to escape.

\section{Results}

The results section has two main parts. Auxiliary simulation results are presented in Section 5.1. The first part consists of grid independence test result, brief comparison of few simulations with different turbulence models for a selected airlift configuration, and finally a comparison of two different closures for the drag force. All of the simulation results discussed in Section 5.1 

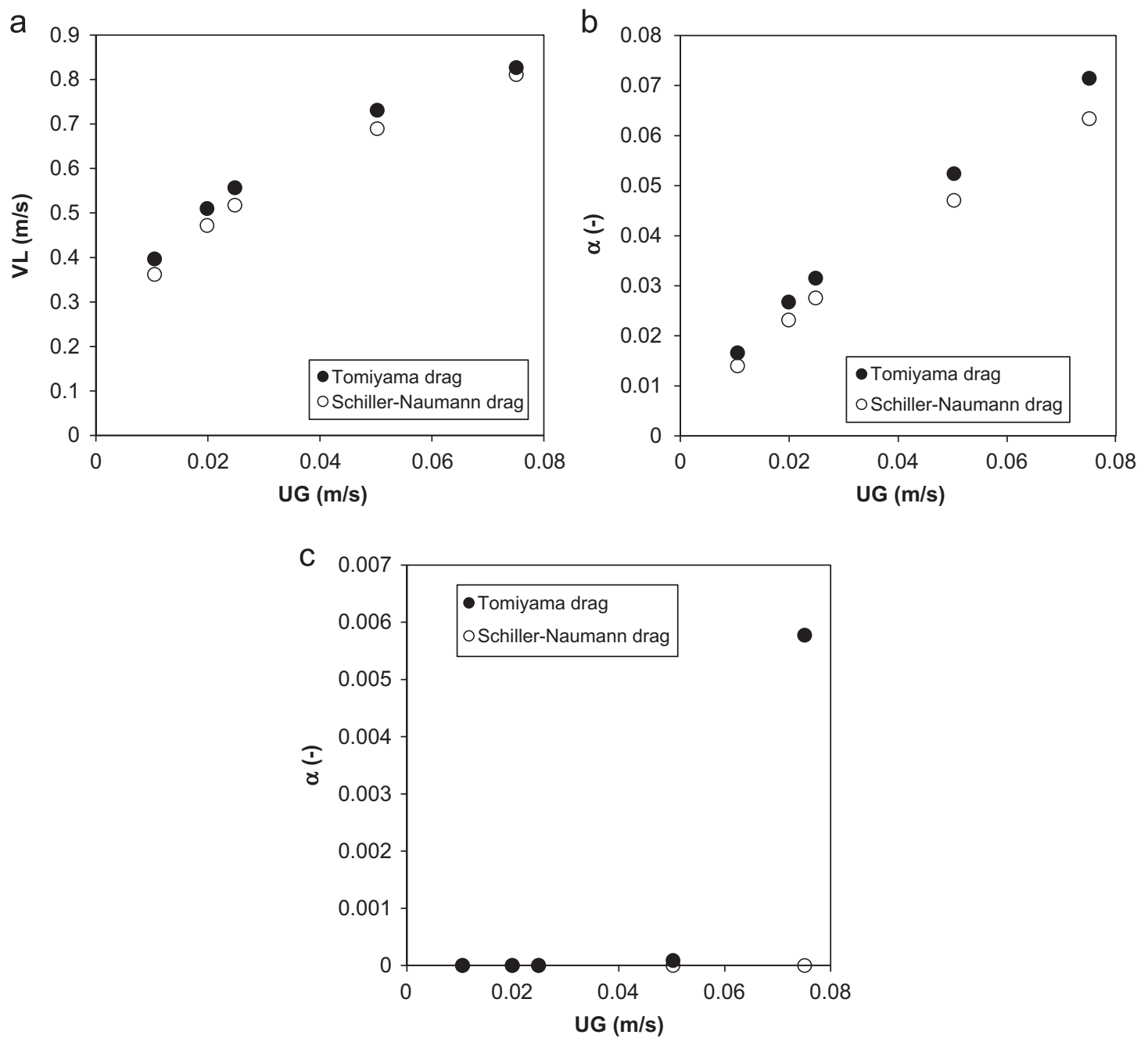

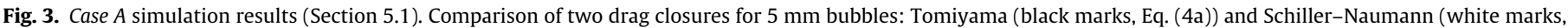
Eq. (4b)). (a) Riser liquid interstitial velocity $V_{L}$, (b) riser gas holdup $\alpha$, and (c) downcomer gas holdup $\alpha$ vs. riser gas superficial velocity $U_{G}$.

were obtained from mixture model simulations done in Fluent 6.3 (see Section 4.1 for simulation setup). The main simulation results and their comparison with experimentally measured data (liquid interfacial velocity and gas holdup in the riser and in the downcomer) are presented in Section 5.2. The results for both simulation setups (Fluent, CFX) are presented. In experiments, there were higher liquid velocities in the downcomer for the larger diameter riser (case $B$ ) (lower downcomer cross section area) and thus gas phase was entrained into the downcomer. If cases $A$ (shorter draft tube) and $C$ (longer draft tube) are compared, then for the longer tube the gas separation was better resulting in no gas in the downcomer, while for the shorter draft tube (case A) bubbles were entrained into the downcomer for the highest gas flow rate.

\subsection{Auxiliary simulation results}

The grid independence test was done for the case $C$ $(1400 \times 62 \mathrm{~cm}$ riser) with riser air superficial velocity $2 \mathrm{~cm} / \mathrm{s}$ (3.6 l/min). One simulation (Fluent) was run on a refined "fine" grid with $8 \times$ more grid cells than in the standard "coarse" grid case (357,600 vs. 44,700 cells). The difference in the liquid interstitial velocity and gas holdup in the riser was within $1 \%$. Thus it could be concluded that the standard grid was sufficient to obtain grid independent results.
Four additional turbulence models in addition to standard $k-\varepsilon$ model were tested for the case $C$, with gas flow rate $3.6 \mathrm{l} / \mathrm{min}$ prior to the main simulation campaign. These four models were RNG $k-\varepsilon$ model, RNG $k-\varepsilon$ model with swirl modification for turbulence viscosity, realizable $k-\varepsilon$ model and standard (not SST) $k-\omega$ model. The models are not described in this paper and reader is referred to Fluent's 6.3 User Guide (Fluent Inc. 2006) for details about these models (simulations were run with default solver settings). The choice of the mentioned turbulence models had only a minor impact on results of the simulations. The largest difference between standard $k-\varepsilon$ model results and the other model results was $1.4 \%$ for interstitial liquid velocity and $4.9 \%$ for gas holdup in riser on "coarse grid" and $1.7 \%$ and $4.9 \%$ on the coarse grid, respectively. Standard $k-\varepsilon$ model was then kept for all subsequent simulations. This turbulence model test was done because of our previous experience with the simulation of a partially aerated rectangular bubble column, where a strong influence of these turbulence models was observed (qualitatively different flow fields, $3 \times$ lower turbulent viscosity predicted by the RNG model if compared to standard $k-\varepsilon$ ). However, the choice of the turbulence model had only a minor impact on the airlift simulation results presented in this paper.

Different closures for drag coefficient were tested on cases A and $C$ to test the effect of changing the bubble slip velocity on simulation results. Tomiyama closure for drag (4) for a single bubble ( $5 \mathrm{~mm}$ equivalent diameter) and Schiller-Naumann 
closure for $5 \mathrm{~mm}$ bubble were compared for case $A$, and Tomiyama closure for 3 and $5 \mathrm{~mm}$ bubble were compared for case $C$. Simulations were done for five gas flow rates in range $1.9-13.6 \mathrm{l} / \mathrm{min}$ for both case $A$ and case $C$.

Case $A$ comparison between the drag closures is shown in Fig. 3a-c (riser liquid interstitial velocity and riser and downcomer gas holdup vs. gas flow rate). We are aware that the SchillerNaumann closure is valid only for rigid spheres, which is certainly not the case of $5 \mathrm{~mm}$ air bubble in water. However, the aim of this comparison was only to examine an influence of changing a slip velocity of bubbles on simulation results. The Tomiyama closures resulted in bubble slip velocities (riser volume average) in range 22.2 to $22.9 \mathrm{~cm} / \mathrm{s}$ depending on the gas flow rate (was lower for higher gas flow rates). The Schiller-Naumann slip velocity was from 37.6 to $38.6 \mathrm{~cm} / \mathrm{s}$, thus $\sim 70 \%$ higher. Nevertheless, even this rather big difference in slip velocities did not cause very significant changes in simulation outputs. The relative difference between the gas holdups in riser was from $11.2 \%$ to $15.8 \%$ and was decreasing with increasing gas flow rate (maximum absolute holdup difference between the two closures was $0.8 \%$ ). The reason for this is the co-current flow of liquid and gas phases in the riser. The gas holdup in the riser is given by $\alpha_{G}=U_{G} / V_{G}$, where $U_{G}$ is gas superficial velocity given by air flow rate into the airlift and $V_{G}$ is gas interstitial velocity in the riser, which is $V_{G}=V_{L}+V_{\text {slip. }}$. The effect of changing the bubble slip velocity $V_{\text {slip }}$ on the holdup in the airlift riser is then smaller then it would be in a case of bubbles rising through a stagnant liquid $\left(V_{L}=0\right)$, because the liquid velocity $V_{L}$ in the riser is relatively high if compared to bubble slip velocity $V_{\text {slip }}$. The situation would be different in the downcomer, where the phases flow countercurrently and the slip velocity value could have significant impact on the downcomer and also the whole airlift hydrodynamics. There was effectively zero gas holdup in the downcomer for all case A gas flow rates except for the highest one with Tomiyama drag correlation, when the gas just started to be entrained into the downcomer, and the downcomer holdup was $\sim 8 \%$ of the riser holdup. The difference between liquid interstitial velocities for the two drag coefficient correlations was from $1.6 \%$ to $8.5 \%$ and was decreasing with increasing of the gas flow rate with a sharper drop of this difference for the highest gas flow rate, where the driving force for liquid circulation was decreased by the small amount of gas entrained into the downcomer (Tomiayama correlation case).

Case $C$ comparison between simulations assuming 3 and $5 \mathrm{~mm}$ diameter bubbles is shown in Fig. 4a and b. Tomiyama drag correlation was used for both. The resulting volume averaged bubble slip velocities in the riser were from 19.4 to $20.0 \mathrm{~cm} / \mathrm{s}$ ( $3 \mathrm{~mm}$ bubble) and from 22.3 to $23.0 \mathrm{~cm} / \mathrm{s}$ ( $5 \mathrm{~mm}$ bubble). There was only a very small difference between 3 and $5 \mathrm{~mm}$ bubble simulations. The reasons for this are the same as described in the previous paragraph. The relative difference between gas holdups in the riser was from $2.2 \%$ to $3.5 \%$, and it was from $0.6 \%$ to $1.8 \%$ for the riser liquid interstitial velocity. Again, the difference was decreasing with increasing of gas flow rate. There was no gas in the downcomer.

It could be concluded that if the gas phase is present only in the riser and not in the downcomer, then the impact of a bubble slip velocity change is not so significant due to co-current flow of both phases. However, if the gas phase is rising through a stagnant liquid or even if the phases are flowing countercurrently (downcomer), then, of course, this impact can be much more significant.

\subsection{Main simulation results-comparison with experiments}

Simulation results for the three airlift configurations (cases $A, B$ and $C$ ) and their comparison with experimentally measured data are presented in this section. Both Fluent and CFX simulation results are
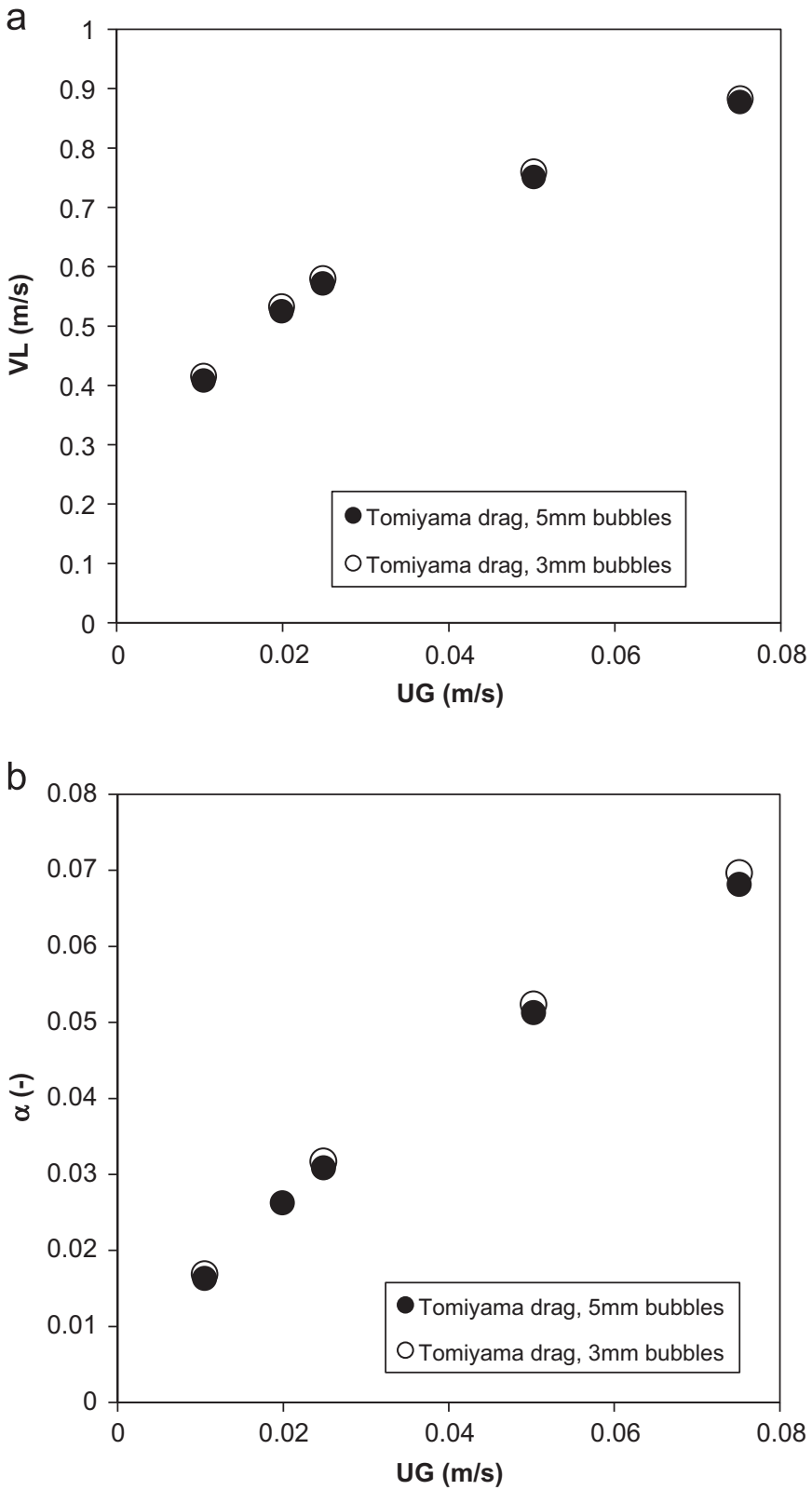

Fig. 4. Case $C$ simulation results (Section 5.1). Tomiyama drag closure (Eq. (4a)) results for $3 \mathrm{~mm}$ (white marks) and $5 \mathrm{~mm}$ bubble (black marks). (a) Riser liquid interstitial velocity $V_{L}$, (b) riser gas holdup vs. riser gas superficial velocity $U_{G}$.

shown for case $A$ and case $C$, simulations of case $B$ were done only in Fluent. Both setups (Fluent, CFX) gave very similar results. Although there was a difference in their results in the radial gas holdup profile, it had only a minor impact on the global holdup and velocity values. In Fluent simulations the gas holdup radial profile was almost completely flat, while in CFX simulations there was a relative difference of $13 \%$ between the riser axis and the riser wall value. This was due to the stronger turbulent dispersion prescribed in the Fluent simulation setup ( $\sigma_{t}$, Eq. (3)). The liquid velocity profiles in CFX and Fluent simulations were similar, with relative difference in the maximal velocity $<3 \%$ (case $\mathrm{A}, U_{G}=7.5 \mathrm{~cm} / \mathrm{s}$ ). Nevertheless, as already pointed out, the global values predicted by CFX and Fluent simulations were almost the same.

Gas flow rates in the simulations were from 1.9 to $13.6 \mathrm{l} / \mathrm{min}$ $(1.05-7.51 \mathrm{~cm} / \mathrm{s}$ gas superficial velocity based on riser cross section) for case $A$ and $C$, and from 1.9 to $26.8 \mathrm{l} / \mathrm{min}(0.53-$ $7.51 \mathrm{~cm} / \mathrm{s}$ ) for case $B$. 

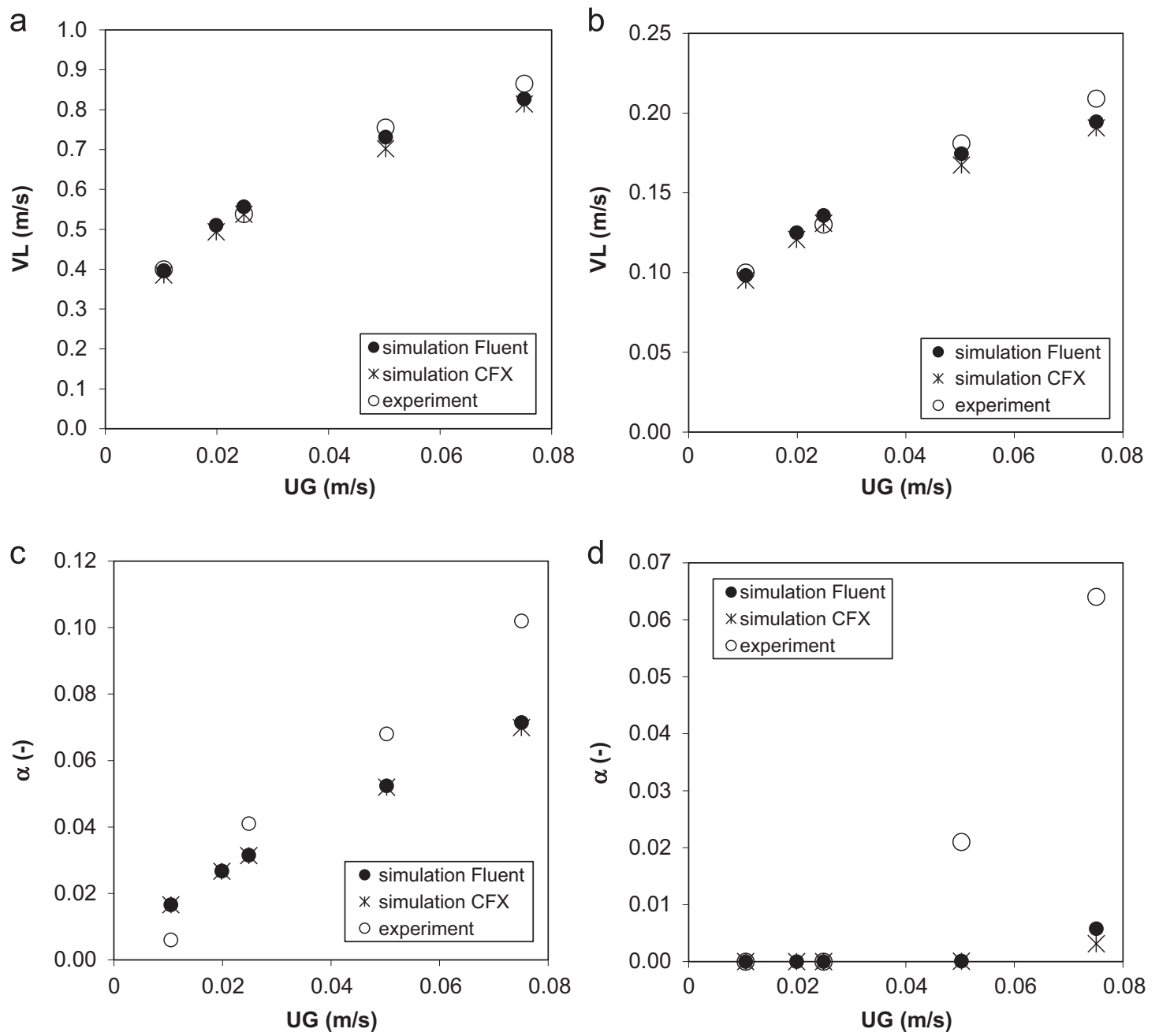

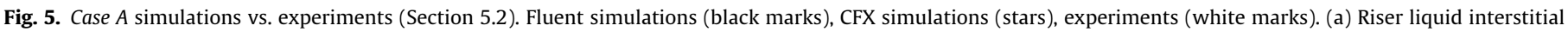
velocity $V_{L}$, (b) downcomer liquid interstitial velocity $V_{L}$, (c) riser gas holdup $\alpha$, and (d) downcomer gas holdup $\alpha$ vs. riser gas superficial velocity $U_{G}$.

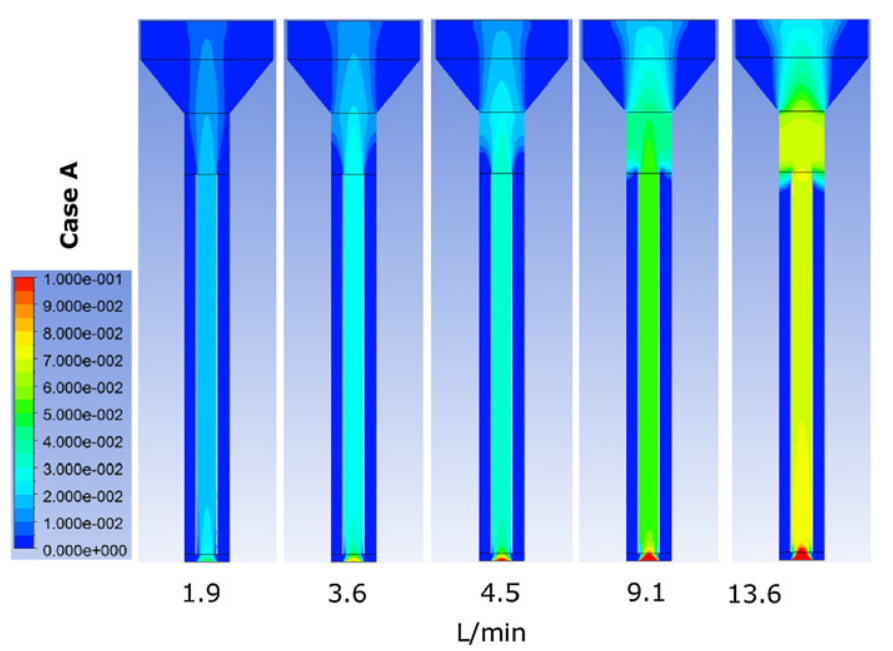

Fig. 6. Case A simulations (Section 5.2): Gas holdup fields for gas flow rates $1.9,3.6,4.5,9.1$ and $13.6 \mathrm{l} / \mathrm{min}$ (riser gas superficial velocity $\sim 1.0,2.0,2.5,5.0$, $7.5 \mathrm{~cm} / \mathrm{s})$.

\subsubsection{Case $A$}

Liquid interstitial velocities and gas holdups in the riser and in the downcomer obtained from simulations (Fluent and CFX) and from experiments as a function of gas flow rate are shown in Fig. 5a-d. Gas holdup fields for different gas flow rates can be seen in Fig. 6. A very good agreement was obtained for liquid interstitial velocity. The relative difference between simulations (Fluent) and experiments was from $0.7 \%$ to $4.4 \%$ and it was increasing with gas flow rate. The Fluent and CFX simulations also agreed very well with each other with CFX predicting slightly lower values. The situation was worse in the case of gas holdup. Simulations strongly underpredicted gas holdup in the riser ( $30 \%$ relative difference for the highest gas flow rate), and also in the downcomer, where the moment, when bubbles are starting to be entrained into the downcomer was shifted to higher gas flow rates in simulations. The gas holdup from simulations in the downcomer for the highest gas flow rate was less than $1 / 10$ of the experimentally obtained value. If a gas interstitial velocity is estimated from $V_{G}=U_{G} / \alpha_{G}$, where $U_{G}$ is the gas superficial velocity given by gas flow rate, and $\alpha_{G}$ is the experimentally measured gas holdup, then for the highest gas flow rate the $V_{G}$ would be $\sim 74 \mathrm{~cm} / \mathrm{s}$, which is actually lower than the measured and simulated liquid velocity and would result in a negative bubble slip velocity, which is of course not possible. The reason of the discrepancy between simulation and experiment is then probably due to the experimental method used to obtain estimates of gas holdups. Holdup estimates measured with U-tube manometers can be negatively influenced by a pressure drop due to flow. This will be discussed at the end of Section 5.2. 

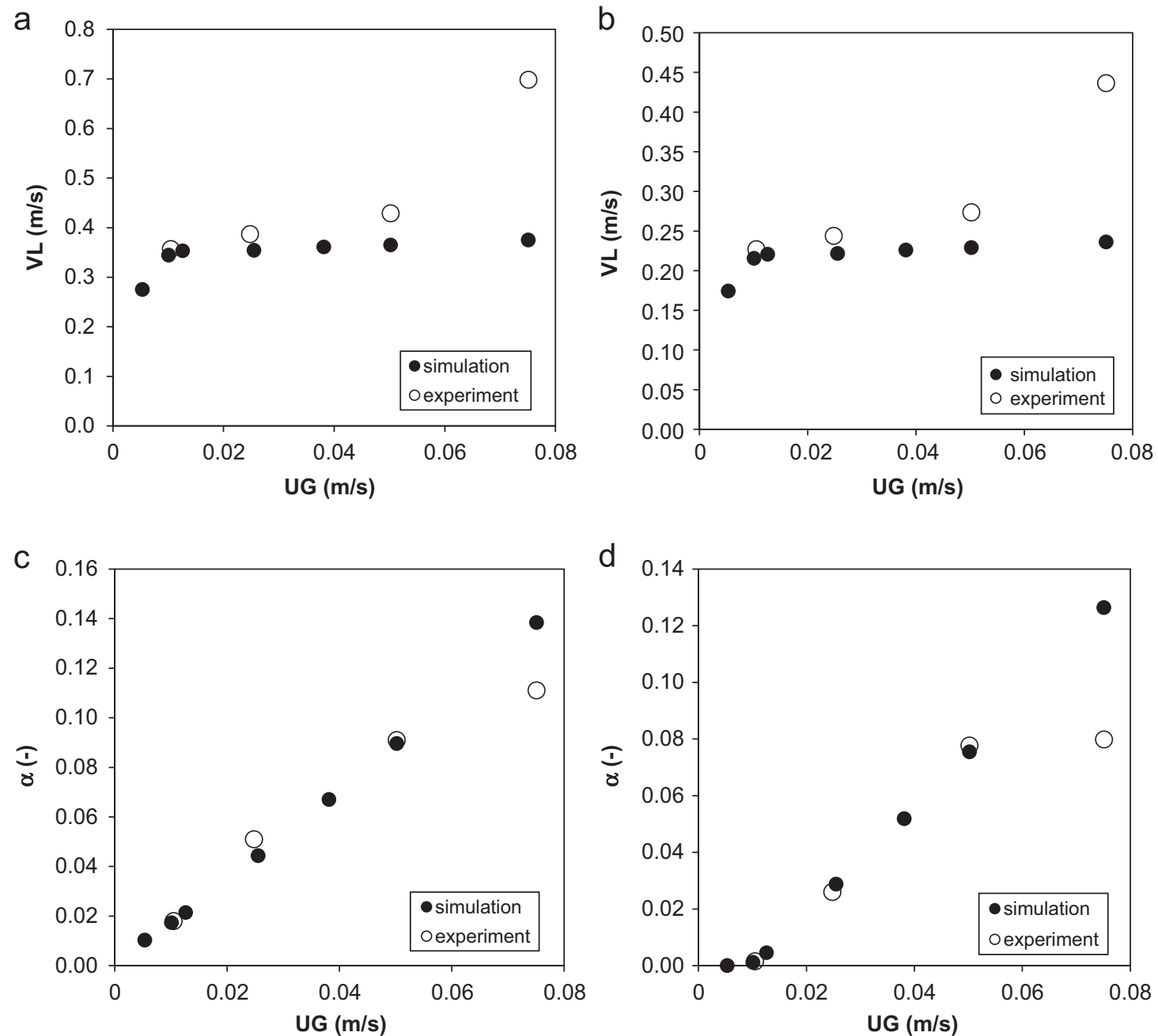

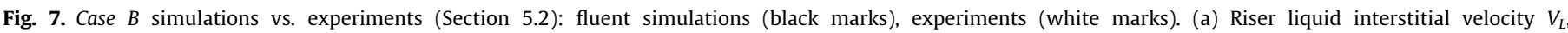
(b) downcomer liquid interstitial velocity $V_{L}$, (c) riser gas holdup $\alpha$, and (d) downcomer gas holdup $\alpha$ vs. riser gas superficial velocity $U_{G}$.

\subsubsection{Case $B$}

The results are shown in Fig. 7a-d (gas holdups and liquid interstitial velocities) and in Fig. 8 (simulated gas holdup fields). This case $B$ is interesting, because three different bubble circulation regimes were experimentally observed with the change of the gas flow rate. At first, for the lowest gas flow rate, there were no gas bubbles inside the downcomer. Then for higher rates the bubbles started to be entrained into the downcomer, but the bubble front did not reach the downcomer bottom yet. And finally, for the highest gas flow rate, the front reached the airlift bottom and bubbles started to circulate with a corresponding change of interstitial liquid velocity and gas holdup vs. gas flow rate curve trends. Now the question was if our simulations are able to capture this behavior. The answer is that they can, but only partially. There was an initially good agreement in liquid interstitial velocities. The difference between the simulation and the experiment for the lowest experimentally measured gas flow rate was $<3.5 \%$ and it was continually increasing with gas flow rate. It was $8.5 \%$ for the second highest flow rate, which is still ok. But for the highest flow rate, where there was a steeper rise of the experimentally measured liquid velocity due to the regime change, the experiment/simulation difference was $46 \%$. Gas holdup in the riser and in the downcomer and also the point at which bubbles start to enter the downcomer was captured very well. However, the agreement for the highest gas flow rate was bad again. The bubble front did not reach the airlift bottom in the

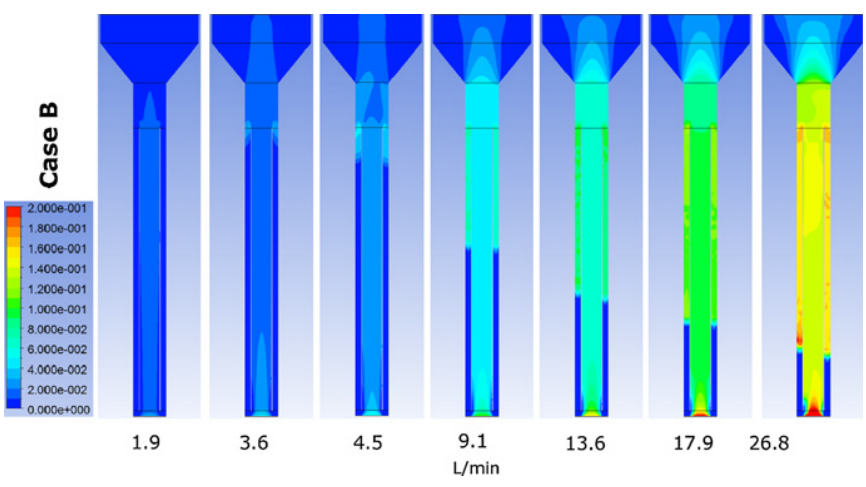

Fig. 8. Case B simulations (Section 5.2): instantaneous gas holdup fields for gas flow rates $1.9,3.6,4.5,9.1,13.6,17.9$ and $26.8 \mathrm{l} / \mathrm{min}$ (riser gas superficial velocity $\sim 0.5,1.0,1.3,2.6,3.8,5.0,7.5 \mathrm{~cm} / \mathrm{s}$ ).

simulations and there appeared no bubble circulation regime even for the maximal gas flow rate. The liquid interstitial velocity did not change much with an increase in the gas flow rate in the simulations, except for the lower rates (only 6.2\% increase from gas flow rate $4.5-26.81 / \mathrm{min}$ ). The liquid superficial velocity in simulations (and thus a total circulating liquid flow rate), was even decreasing with gas flow rate. The reason was that the 
driving force for the liquid circulation, the difference between average holdups in the riser and in the downcomer, was slowly decreasing with gas flow rate from a certain point $\left(Q_{G}=4.5 \mathrm{l} / \mathrm{min}\right.$, $U_{G}=1.26 \mathrm{~cm} / \mathrm{s}$ ), while the gas holdups in the riser and the downcomer were rising linearly. The absolute difference between them (riser/downcomer) was $1.7 \%$ at $Q_{G}=4.5 \mathrm{l} / \mathrm{min}\left(U_{G}=1.26 \mathrm{~cm} / \mathrm{s}\right)$ and $1.2 \%$ at $26.8 \mathrm{l} / \mathrm{min}\left(U_{G}=7.51 \mathrm{~cm} / \mathrm{s}\right)$. The liquid superficial velocity in the riser dropped from 34.6 to $32.3 \mathrm{~cm} / \mathrm{s}$ in this gas flow rate range in simulations.

For case $B$ simulations, there was a very good agreement with experiments for low gas flow rates. The deviation from experiments then started to increase slowly with gas flow rate and then it rose suddenly for the highest gas flow rate with the onset of a bubble circulation regime, which was not captured by the simulations. As it was pointed out earlier, flow in a downcomer (countercurrent flow) is influenced by a bubble slip velocity much more than a flow in a riser (co-current). Demands on the accuracy of drag force closure are then quite high if bubbles are present in the downcomer. Drag coefficient and bubble slip velocity for given fluids depend on bubble size, shape and on local gas holdup (and other factors such as a presence of surfactants). To obtain a correct bubble slip velocity (a) a reliable closure equation for it is needed and (b) correct inputs into this closure are required. Our closure was Eq. (3). A bubble size can be either prescribed directly or it can be a result from a bubble coalescence/break-up model solution. The local gas holdup is then provided by solving governing equations of the flow. In our simulations the bubble size was prescribed directly $(5 \mathrm{~mm}$ for all flow rates, all bubbles assumed to have a same size). The weak point of our simulations and the cause of disagreement between simulations and experiments can be any of the above mentioned issues, probably the specification of bubble size and/or the slip velocity adjustment on the local gas holdup. Although measurements of bubble size were done with a high speed camera, they could be done only for very low gas flow rates. The bubbly layer soon became opaque as the holdup increased. Nevertheless, if extrapolated for the higher flow rates, and taking into account the weak dependency of the bubble rise velocity on the bubble diameter in range of bubble equivalent diameters cca 4-10 mm (see e.g. Jamialahmadi et al., 1994), our assumption was that the $5 \mathrm{~mm}$ fixed bubble size can reasonably well represent the typical bubble slip velocities encountered in the airlift. When the bubbles were entrained into the downcomer, this assumption was probably too crude.

\subsubsection{Case $C$}

Simulations (Fluent and CFX) and experiments of case $C$ are compared in Fig. 9a-c. Gas holdup fields for different gas flow rates can be seen in Fig. 10. A good simulation/experiment agreement was obtained for liquid interstitial velocity. The relative difference between simulations (Fluent) and experiments varied from $4.6 \%$ to $8.3 \%$. And again, as for the case $A$, the Fluent
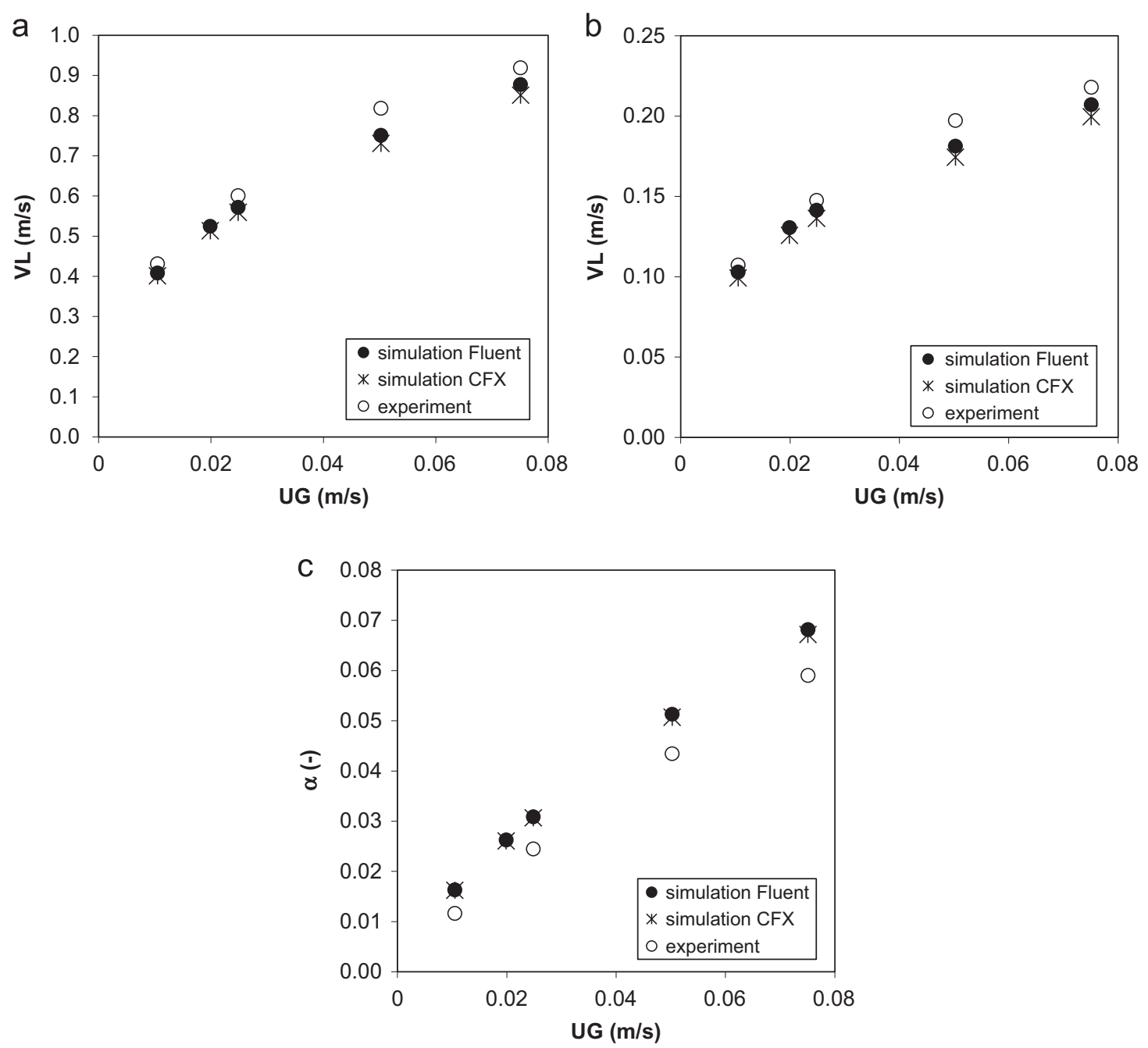

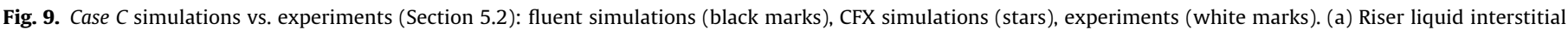
velocity $V_{L}$, (b) downcomer liquid interstitial velocity $V_{L}$, and (c) riser gas holdup $\alpha$ vs. riser gas superficial velocity $U_{G}$. 


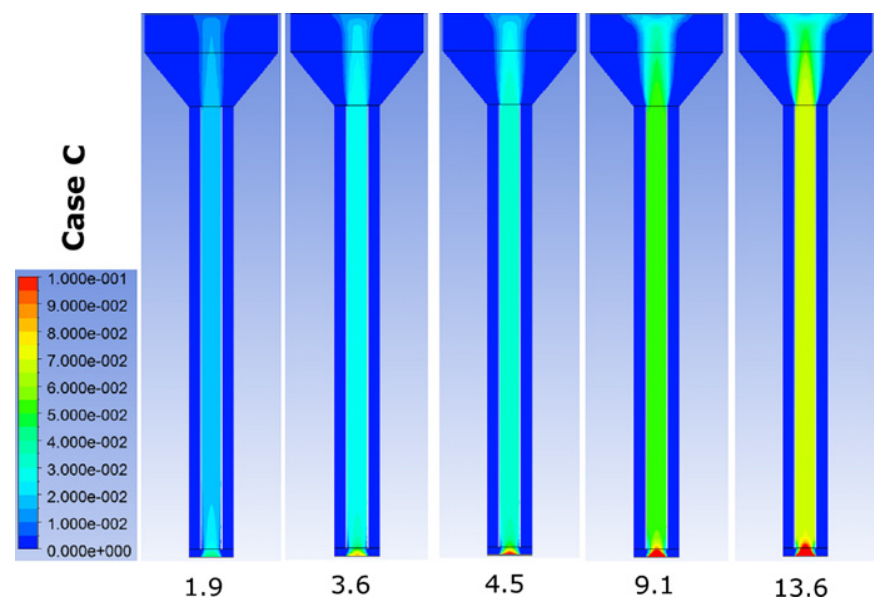

Fig. 10. Case $C$ simulations (Section 5.2): gas holdup fields for gas flow rates 1.9, 3.6, 4.5, 9.1 and $13.6 \mathrm{l} / \mathrm{min}$ (riser gas superficial velocity $\sim 1.0,2.0,2.5,5.0,7.5 \mathrm{~cm} / \mathrm{s}$ ).

and CFX simulations gave very similar results with CFX predicting slightly lower values of liquid interstitial velocity. The agreement between the simulated and experimentally measured gas holdup in the riser was poor. The relative difference in the riser holdup for the lowest gas flow rate was $40.4 \%$ and continually decreased to $15.5 \%$ for the highest gas flow rate. Unlike as in the case $A$, the gas holdup in case $C$ was overpredicted by simulations. If case $C$ simulations are compared with case $A$ simulations (case $C$ has $20 \mathrm{~cm}$ longer draft tube), then it can be noticed that the predicted liquid interstitial velocities are very similar, with case $C$ velocities 2.7-2.9\% higher if compared to case $A$ except for the highest gas flow rate, where the case $C$ velocity is $6.1 \%$ higher, because of starting bubble penetration into the downcomer in case $A$. Experimentally measured riser liquid interstitial velocities for case $C$ were $6.3-11.6 \%$ higher than for case $A$ depending on the gas flow rate. If the same comparison is done for gas holdups (case $A$ vs. case $C$ ) then the relative difference between case $A$ and case $C$ simulations is again low (case $C$ riser holdup 1.7-4.6 relative \% lower). However, the experimentally measured holdup in case $C$ was 24.7-33.2 relative \% lower than in case A except for the lowest gas flow rate. Thus the difference between case $A$ and case $C$ in experiments was much higher than in simulations. It may suggest that the reason for bigger discrepancy between experimental and simulation data in case $C$ is probably again a consequence of the experimental method used to estimate gas holdups (U-tube manometers). As it was already said, holdup estimates measured with U-tube manometers can be negatively influenced by a pressure drop due to flow.

One of the sources of error involved in using the U-tube manometer is the pressure drop due to flow. Usually the pressure drop effect is neglected. It was done also in measurements presented in this paper. If the pressure drop in the riser is estimated as a pressure drop for a fully developed single phase flow in a pipe (turbulent flow, hydraulically smooth pipe) using the measured liquid velocities, then the estimates for the pressure drop (taken for $1.2 \mathrm{~m}$ pipe length) for $7.5 \mathrm{~cm} / \mathrm{s}$ gas superficial velocities would be $\sim 150 \mathrm{~Pa}$ (case A), $\sim 70 \mathrm{~Pa}$ (case B), and $\sim 165 \mathrm{~Pa}$ (case $C$ ). This would mean an underprediction of the real gas holdup due to the pressure drop error by $\sim 1.3-1.4 \%$ for cases $A$ and $C$, and $\sim 0.6 \%$ for case $B$ (in absolute values not relative). These are the maximal estimated errors for the three configurations due to pressure drop and would be lower for the lower gas flow rates and the resulting lower liquid circulation rates. This would mean a better agreement between the simulation and the experiment for the case $C$ holdup, if the pressure drop

correction would be accounted for. Regarding the case $B$, not much would be changed, because there is smaller pressure drop due to larger riser diameter. The agreement would get worse for the case $A$, if the pressure drop correction would be included. The source of error in the case $A$ experimental measurements is probably different than the pressure drop.

\section{Conclusions}

The primary goal was to test the ability of our CFD simulation setup to capture global characteristics of the flow in our experimental 501 internal loop airlift with enlarged degassing zone in the three experimentally observed bubble circulation regimes, and to verify if the simulation setup could be later used for obtaining the global flow characteristic for modified geometries of our original airlift design or for different fluids. The secondary goal was to test the sensitivity of the simulations to the different bubble slip velocity, and to the different turbulence closure models (variants of $k-\varepsilon, k-\omega$ ).

It was shown that there was a good agreement regarding the liquid interstitial velocities in the riser and the downcomer with errors mostly well below $10 \%$ with an exception of higher gas flow rates (and especially the highest one) in case $B$ (larger diameter riser). The agreement between simulations and experiments of the gas holdups in the riser and the downcomer was poorer. The simulations overpredicted the riser gas holdup in case $A$ and underpredicted it in case $C$. However, as it was discussed in the results section, it could be an error in experimental measurements rather than a simulation error. The agreement of the gas holdups in both the riser and the downcomer for case $B$ was surprisingly good, except for the highest gas flow rate, where a flow regime had already changed to a bubble circulation regime, which was not captured by simulations. To conclude, the employed simulation setups were able to predict reasonably well situations, when there was no gas phase entrained into the downcomer. Care must be taken however, if the airlift operates in the other two bubble circulation regimes. It was shown that there was only a weak influence of the bubble slip velocity (and thus the drag coefficient) on the simulation results in cases with zero downcomer gas holdup. The reason for this weak influence is the co-current flow of the gas and the liquid phase in the riser. The phases flow countercurrently in the downcomer and then for the cases with nonzero downcomer gas holdup a more accurate modeling of the drag force/bubble slip velocity, probably in connection with a bubble break-up coalescence model, would be needed to obtain better agreement with experiments. Three versions of the $k-\varepsilon$ turbulence model and one $k-\omega$ model were tested. The choice of the turbulent model had only a minor impact on the simulation results.

\section{Nomenclature}

$\mathbf{a}$

$d$

$f$

$C_{D}$

D

g

G

$H$

$k$ K $\mathbf{M}$

\author{
acceleration $\left(\mathrm{m} \mathrm{s}^{-2}\right)$ \\ bubble (equivalent) diameter (m) \\ drag function $(-)$ \\ drag coefficient $(-)$ \\ distance, diameter ( $\mathrm{m}$ ) \\ acceleration due to gravity $\left(\mathrm{m} \mathrm{s}^{-2}\right)$ \\ turbulent kinetic energy production due to mean \\ velocity gradient $\left(\mathrm{J} \mathrm{m}^{-3} \mathrm{~s}^{-1}\right)$ \\ distance, height $(\mathrm{m})$ \\ turbulent kinetic energy $\left(\mathrm{m}^{2} \mathrm{~s}^{-2}\right)$ \\ momentum transfer coefficient $\left(\mathrm{kg} \mathrm{m}^{-3} \mathrm{~s}^{-1}\right)$ \\ force one phase is acting on another phase $\left(\mathrm{N} \mathrm{m}^{-3}\right)$
}




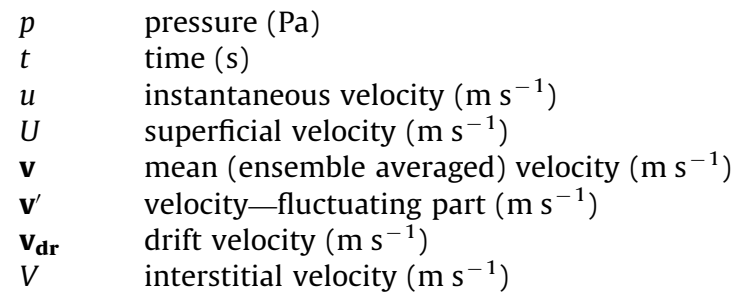

\section{Greek letters}

$\alpha \quad$ phase volume fraction, gas holdup (-)

$\varepsilon \quad$ turbulence dissipation rate (-)

$\mu \quad$ molecular dynamic viscosity (Pa s)

$\mu_{t} \quad$ turbulent dynamic viscosity (Pa s)

$v_{\mathrm{t}} \quad$ turbulent kinematic viscosity $\left(\mathrm{m}^{2} \mathrm{~s}^{-1}\right)$

$\rho \quad$ fluid density $\left(\mathrm{kg} \mathrm{m}^{-3}\right)$

$\sigma \quad$ surface tension $\left(\mathrm{N} \mathrm{m}^{-1}\right)$, constants in turbulence models (-)

$\tau \quad$ particle relaxation time (s)

\section{Subscripts}

$\begin{array}{ll}c & \text { continuous phase } \\ d & \text { dispersed phase } \\ D & \text { drag (force) } \\ i, k & \text { index of a phase } \\ m & \text { mixture property } \\ T D & \text { turbulent dispersion (force) } \\ L & \text { liquid } \\ G & \text { gas }\end{array}$

\section{Others}

$\begin{array}{ll}\text { Eo } & \text { Eotwos number } \\ \text { Re } & \text { Reynolds number }\end{array}$

\section{Acknowledgements}

We gratefully acknowledge the financial support of GACR (Grant no. 104/07/1110) and from FCT (Fundacão para a Ciência e Tecnologia, SFRH/BD/37082/2007). We also wish to thank our colleague $\mathrm{S}$. K. Orvalho for reading the manuscript and providing valuable feedback.

\section{References}

Blazej, M., Kisa, M., Markos, J., 2004J. Scale influence on the hydrodynamics of an internal loop airlift reactor. Chemical Engineering and Processing 43, 1519-1527.

Cao, C., Dong, S., Guo, Q., 2007. Experimental and numerical simulation for gasliquid phases flow structure in an external-loop airlift reactor. Industrial \& Engineering Chemistry Research 46, 7317-7327.
Chisti, Y., 1989. Airlift Bioreactors.. Elsevier, London.

Chisti, Y., 1998. Pneumatically agitated bioreactors in industrial and environmental bioprocessing: hydrodynamics, hydraulics, and transport phenomena. Applied Mechanics Reviews 51 (1), 33-112.

Fluent Inc., 2006. Fluent 6.3 User's Guide.

Freitas, C., Fialova, M., Zahradnik, J., Teixeira, J.A., 2000. Hydrodynamics of a threephase external-loop airlift bioreactor. Chemical Engineering Science 55, 4961-4972.

Heijnen, J.J., Hols, J., van der Lans, R.G.J.M., van Leeuwen, H.L.J.M., Mulder, A., Weltevrede, R., 1997. A simple hydrodynamic model for the liquid circulation velocity in a full-scale two- and three-phase internal airlift reactor operating in the gas recirculation regime. Chemical Engineering Science 52, 2527-2540.

Huang, Q., Yang, Ch., Yu, G., Mao, Z.S., 2008. Sensitivity study on modeling an internal airlift loop reactor using a steady 2D two-fluid model. Chemical Engineering and Technology 31, 1790-1798.

Huang, Q., Yang, Ch., Yu, G., Mao, Z.S., 2010. CFD simulation of hydrodynamics and mass transfer in an internal airlift loop reactor using a steady two-fluid model. Chemical Engineering Science 65, 5527-5536.

Jamialahmadi, M., Branch, C., Muller-Steinhagen, H., 1994. Terminal bubble rise velocity in liquids. Trans IChemE 721 (Part A), 119-122.

Jia, X., Wen, J., Wei, F., Yuan, Q., 2007. Local hydrodynamics modeling of gasliquid-solid three-phase airlift loop reactor. Industrial \& Engineering Chemistry Research 46, 5210-5220.

Lin, J., Han, M., Wang, T., Zhang, T., Wang, J., Jin, Y., 2004. Influence of the gas distributor on the local hydrodynamic behavior of an external loop airlift reactor. Chemical Engineering Journal 102, 51-59.

Luo, H.P., Al-Dahhan, M.H., 2008. Local characteristics of hydrodynamics in draft tube airlift bioreactor. Chemical Engineering Science 63, 3057-3068.

Luo, H.P., Al-Dahhan, M.H., 2010X. Local gas holdup in a draft tube airlift bioreactor. Chemical Engineering Science 65, 4503-4510.

Manninen, M., Taivassalo, V., Kallio, S., 1996. On the Mixture Model for Multiphase Flow, 288. VTT Publications Technical Research Centre of Finland.

Merchuk, J.C., Contreras, F., Garcia, F., Molina, E., 1998. Studies of mixing in a concentric tube airlift bioreactor with different spargers. Chemical Engineering Science 53, 709-719.

Mudde, R.F., van den Akker, H.E.A., 2001. 2D and 3D simulations of an internal airlift loop reactor on the basis of a two-fluid model. Chemical Engineering Science 56, 6351-6358.

Oey, R.S., Mudde, R.F., Portela, L.M., van den Akker, H.E.A., 2001. Simulation of a slurry airlift using a two-fluid model. Chemical Engineering Science 56, 673-681.

Roy, S., Dhotre, M.T., Joshi, J.B., 2006. CFD Simulation of flow and axial dispersion in external loop airlift reactor. Chemical Engineering Research and Design 84, 677-690.

Sokolichin, A., Eigenberger, G., Lapin, A., 2004. Simulation of buoyancy driven bubbly flow: established simplifications and open questions. AIChE Journal 50, $24-45$.

Talvy, S., Cockx, A., Line, A., 2007. Modeling hydrodynamics of gas-liquid airlift reactor. AIChE Journal 53, 335-353.

Tomiyama, A., Tamai, H., Zun, I., Hosokawa, S., 2002. Transverse migration of single bubbles in simple shear flows. Chemical Engineering Science 57, 1849-1858.

Utiger, M., Stuber, F., Duquenne, A.-M., Delmas, H., Guy, Ch., 1999. Local measurements for the study of external loop airlift hydrodynamics. Canadian Journal of Chemical Engineering 77, 375-382.

van Baten, J.M., Ellenberger, J., Krishna, R., 2003. Hydrodynamics of internal air-lift reactors: experiments versus CFD simulations. Chemical Engineering and Processing 42, 733-742.

van Benthum, W.A.J., van der Lans, R.G.J.M., van Loosdrecht, M.C.M., Heijnen, J.J., 1999. Bubble circulation regimes in an internal-loop airlift reactor. Chemical Engineering Science 54, 3995-4006.

Verlaan, P., Tramper, J., VanT Reit, K., Luyben, K.C.H.A.M., 1986. A hydrodynamic model for an airlift-loop bioreactor with external loop. Chemical Engineering Journal 33, B43-B53.

Vial, Ch., Poncin, S., Wild, G., Midoux, N., 2002. Experimental and theoretical analysis of the hydrodynamics in the riser of an external loop airlift reactor. Chemical Engineering Science 57, 4745-4762.

Wang, T., Wang, J., Zhao, B., Ren, F., Jin, Y., 2004. Local hydrodynamics in an external loop airlift slurry reactor with and without a resistance-regulating element. Chemical Engineering Communications 191, 1024-1042.

Young, M.A., Carbonell, R.G., Ollis, D.F., 1991. Airlift bioreactors: analysis of local two-phase hydrodynamics. AIChE Journal 37 (3), 403-428. 